\title{
Survey of symptomatic dermatologic disease in homeless patients at a shelter-based clinic
}

\author{
Caitlin Contag*, Stefan E. Lowenstein*, Sharad Jain, Erin H. Amerson
}

Department of Dermatology, University of California, San Francisco, CA, USA

Corresponding author: Erin H. Amerson, MD, E-mail: Erin.Huiras@ucsf.edu

\begin{abstract}
This study aimed to survey the range of skin disorders diagnosed at a San Francisco clinic based in a temporary homeless shelter. We retrospectively reviewed 254 charts documenting encounters from 2011-2015 and collected demographic and historical data, along with skin disease morphology and location, clinical diagnosis, and recommended therapies. Of 254 charts reviewed, 136 (53.3\%) recorded a dermatologic complaint. Diagnostic categories from most to least prevalent were inflammatory dermatoses, superficial fungal infections, wounds and trauma, infestations, bacterial infections, neoplasms, and viral infections. The most prevalent body location of the skin complaint was the lower extremity. The high prevalence of dermatologic disease underscores the importance of expanding dermatologic care for unhoused individuals. Many of the cutaneous diseases were preventable or treatable with low-cost interventions. The frequency of skin conditions affecting the lower extremity suggests that a foot and leg exam should be routine in clinical encounters with homeless patients.
\end{abstract}

Key words: Dermatitis; Tinea; Scabies

\section{INTRODUCTION}

The US Department of Housing and Urban Development estimates over half a million individuals are homeless in the United States [1]. Individuals experiencing homelessness face many threats to their health, and skin-related issues are among the most common health-care complaints in this population [2]. Lack of stable housing puts individuals at risk for skin problems associated with exposure to the elements, difficulties with personal hygiene and access to bathing, and crowded conditions. Co-morbid substance use and mental illness also negatively impact skin health [3], and together with stigma and distrust of the health care system, may lead to delays in seeking care [4]. One study conducted in a cohort of homeless individuals found that nearly $60 \%$ had not seen a physician in the past five years [5]. Dermatologic diseases often have psychological and functional consequences [6] and may further marginalize an already vulnerable individual.
While there is extensive literature supporting the negative impact dermatologic conditions have on quality of life [7], and the negative impact of homelessness on general health [8], few studies have assessed the prevalence of skin disease in homeless populations. A 1999 survey of 142 homeless men in a Boston shelter who volunteered for a free skin examination identified tinea pedis, pitted keratolysis of the feet, traumatic injuries, toenail onychomycosis, acne vulgaris, and seborrheic dermatitis as the most common skin conditions [9]. However, the authors noted that a majority of sheltered homeless individuals had normal exam findings, which they attributed to care provided by the shelter. A 2005 cross-sectional study of skin infections in a French shelter found bacterial infections secondary to pruritus and scratching, bodylice infestations, folliculitis, tinea pedis, scabies, and impetigo more frequently in the homeless population when compared with a housed control population [10]. A 2012 retrospective review of charts from 82 patients

*The first two authors listed are considered joint-first authors and contributed equally to the manuscript

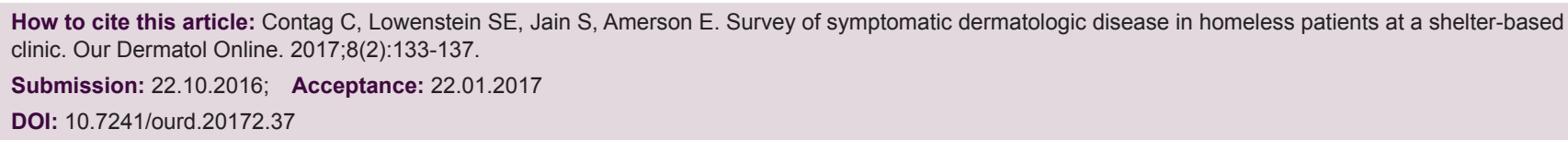


(22 homeless) seen in a referral-based, volunteer-run dermatology clinic in Venice, California, noted a higher rate of malignant and pre-malignant neoplasms among homeless compared with housed individuals. This small study found no statistically significant difference in infectious and non-infectious dermatoses when comparing housed and homeless patients [11].

In summary, little work has been done to determine the prevalence of skin disease in sheltered homeless populations. We sought to add to the literature by surveying symptomatic skin disease in a sample of homeless persons seeking medical care at a shelter-based clinic in San Francisco.

\section{METHODS}

We performed a retrospective chart review of patients seen at the University of California, (UCSF) StudentRun Clinic at the Multi Service Center (MSC)-South Homeless Shelter in San Francisco. Two types of clinics conducted at the shelter were included in this study. A general medicine clinic is held two evenings each week throughout the year, and a dermatology clinic is held on a different evening every other week. Approximately 10-12 adult patients are seen during each clinic. Either an internal medicine or family medicine resident or attending physician supervises the general medicine clinic. Either a dermatology resident or attending physician supervises the dermatology clinic. Medical students walk through the shelter and actively recruit patients for both the dermatology clinic and general medicine clinic. Shelter residents are selected for the dermatology clinic by medical students inquiring, "Would you like to see a skin doctor?" All care providers at the clinic are volunteers.

Progress notes are written by medical students, attested by a licensed physician, and stored in a locked file cabinet. Admixed notes from both the general clinic and the dermatology clinic are filed by patient name in alphabetical order. The notes are not labeled by clinic type; thus notes from both the general medicine and dermatology clinics were reviewed.

Patient encounters from 2011-2015 were evaluated for inclusion in the study. All notes with dermatologic diagnoses from patients with last names beginning with the letters " $\mathrm{A}$ " and " $\mathrm{B}$ " were assessed in order to estimate the frequency of skin diagnoses in the progress notes. Subsequently, every tenth note from patients with names starting with letters "C" to "Z," was evaluated.
If the tenth note did not have a skin related complaint, then another group of ten notes was counted until a note with a dermatologic diagnosis was found.

Patients were included in the study if the following conditions were met in the encounter note: a dermatologic complaint or diagnosis was documented, and age, gender, and date of service were recorded. Patients with more than one encounter for a single occurrence of a diagnosis were only included once in the survey. If the patient presented later with an additional complaint, then this counted as a second encounter and diagnosis. Additional data collected from the charts when available included: ethnicity, chief complaint, illicit drug use, history of present illness, past medical history, lesion morphology and location, and treatments/interventions. Each patient included in the study was assigned a unique patient identification number, which was marked on their charts. The key linking ID to patient name was stored in accordance with Health Insurance Portability and Accountability Act (HIPAA) regulations, and was destroyed at the end of the study. Due to the high number of patients lost to follow-up, and the high number of patients with outdated or missing contact information, it was not practical to obtain informed consent from patients, and patients were not contacted for follow-up. After collection, these data were evaluated to determine the most common diagnoses. The study was approved by the Committee for Human Research at UCSF.

\section{RESULTS}

\section{Dermatologic Diagnoses}

Of the 423 charts reviewed, 169 charts were associated with clinic visits solely for placement or reading of tuberculin skin tests and were excluded from the study. The remaining 254 charts were evaluated for inclusion. Over half of the 254 remaining charts were associated with visits to the clinic for dermatological complaints or visits resulting in dermatologic diagnoses $(n=136,53.5 \%)$. Some patients included had multiple encounters for different skin-related complaints, resulting in 136 dermatology diagnoses in a total of 100 patients.

\section{Demographics}

Ages ranged from 19 to 78 , with the mean patient age being 48.7 years. Of the 100 patients, 74 identified as male, 25 identified as female, and one patient 
identified as male to female transgender. A significant number of notes did not document ethnicity $(n=43)$. Of the encounters with ethnicity recorded, the most common was "White" $(n=26)$ and "Black" $(n=17)$, and the least common was "Native American" $(\mathrm{n}=2)$ and "Asian" $(\mathrm{n}=2)$.

\section{Dermatologic Diagnoses and Location}

We grouped diagnoses into the following etiologic classes: inflammatory dermatoses $(n=36)$, superficial fungal infections $(n=34)$, wounds and trauma $(n=26)$, infestations $(n=19)$, bacterial infections $(n=18)$, neoplasms $(n=6)$, and viral infections $(n=3)$. Miscellaneous conditions $(n=20)$ were used to categorize diagnoses not included in other etiologic classes. Tinea pedis $(n=22)$ was the most common diagnosis. Other common diagnoses were xerosis (12), lichen simplex chronicus (9), abscesses $(n=9)$, lacerations (8) and arthropod bites (7). No premalignant or malignant neoplasms were diagnosed in the patient cohort (Table 1). The most common body site for any diagnosis was the lower extremity $(n=49,47.1 \%)$. The second most common site was the upper extremity (Table 2).

\section{Interventions}

Topical steroids were the most commonly administered medications followed by topical antifungals and emollients. Personal care items including socks, bandages, and sunscreen were also frequently dispensed. Oral antibiotics and analgesics were least frequently used (Table 3).

\section{CONCLUSIONS}

Our data agree with the existing literature that dermatologic care is an important dimension of healthcare for underserved and unhoused populations. More than half of patients receiving medical care in our homeless clinic had dermatologic complaints or diagnoses. Similar to previous studies, our study suggests that infections, particularly superficial fungal infections, are very common, as are inflammatory dermatoses and wounds/trauma. Compared to the study by Grossberg et al. from southern California, where actinic keratosis and skin cancers made up $25 \%$ of the diagnoses; no skin cancers were identified in the charts we surveyed. There are several possible reasons for this finding.

Table 1: Diagnoses grouped by etiologic class. Some subjects received multiple diagnoses

\begin{tabular}{|c|c|c|c|}
\hline Etiologic class & \# of cases (\%) & Diagnoses & \\
\hline \multirow[t]{5}{*}{ Inflammatory dermatoses } & $36(22.2)$ & Lichen simplex chronicus (9) & Contact dermatitis (3) \\
\hline & & Psoriasis (7) & Actinic prurigo (1) \\
\hline & & Atopic dermatitis (5) & Cystic acne (1) \\
\hline & & Dermatitis, unspecified (4) & Hidradenitits suppurativa (1) \\
\hline & & Seborrheic dermatitis (4) & Opiate-induced pruritis (1) \\
\hline \multirow[t]{3}{*}{ Superficial fungal infections } & $34(21.0)$ & Tinea pedis (22) & Tinea barbae (1) \\
\hline & & Onychomycosis (8) & Tinea cruris (1) \\
\hline & & Cutaneous candidiasis (2) & \\
\hline \multirow[t]{5}{*}{ Wounds and trauma } & $26(16.0)$ & Lacerations (8) & Anogenital fissure (2) \\
\hline & & Surgical wounds (4) & Callus (1) \\
\hline & & Abrasions (3) & Diabetic ulcer (1) \\
\hline & & Blisters (3) & Nail hematoma (1) \\
\hline & & Ulcer, unspecified (3) & \\
\hline \multirow[t]{4}{*}{ Miscellaneous } & $20(12.3)$ & Xerosis (12) & Edema (1) \\
\hline & & Nail dystrophism (2) & Lymphadenopathy (1) \\
\hline & & Painful rash, unspecified (2) & Sunburn (1) \\
\hline & & Blistering rash, unspecified (1) & \\
\hline \multirow[t]{3}{*}{ Infestations } & $19(11.7)$ & Arthropod bite (7) & Pediculosis capitis (2) \\
\hline & & Scabies (5) & Bed bugs (1) \\
\hline & & Pediculosis corporis (3) & Pediculosis pubis (1) \\
\hline \multirow[t]{2}{*}{ Bacterial infections } & $18(11.1)$ & Abscess (9) & Folliculitis (2) \\
\hline & & Cellulitis (6) & $\begin{array}{l}\text { Soft tissue infection, } \\
\text { unspecified (1) }\end{array}$ \\
\hline \multirow[t]{3}{*}{ Neoplasms } & $6(3.7)$ & Unspecified (2) & Intradermal nevus (1) \\
\hline & & Angiofibroma (1) & Lipoma (1) \\
\hline & & Cherry angioma (1) & \\
\hline \multirow[t]{2}{*}{ Viral Infections } & $3(1.9)$ & Herpes labialis (1) & Plantar warts (1) \\
\hline & & Herpes zoster (1) & \\
\hline Total & 162 & & \\
\hline
\end{tabular}


www.odermatol.com

Table 2: Distribution of the six most frequent diagnostic categories by body site, excluding arthropod bites. Some patients had primary lesions distributed over multiple locations

\begin{tabular}{|c|c|c|c|c|c|}
\hline Diagnosis & Lower extremity $(n=49)$ & Upper extremity $(n=25)$ & Trunk $(n=11)$ & Head $(n=11)$ & Other $(n=8)$ \\
\hline Injuries $(n=21)$ & 7 & 6 & 1 & 4 & 3 \\
\hline Chronic wounds $(n=8)$ & 6 & 1 & 0 & 0 & 1 \\
\hline Cellulitis $(n=7)$ & 4 & 3 & 0 & 0 & 0 \\
\hline Abscesses $(n=9)$ & 5 & 4 & 0 & 0 & 0 \\
\hline Dermatitis $(n=15)$ & 2 & 1 & 7 & 4 & 1 \\
\hline Fungal infections $(n=44)$ & 25 & 10 & 3 & 3 & 3 \\
\hline
\end{tabular}

Table 3: Medications and personal care items dispensed

\begin{tabular}{lcl}
\hline Intervention & Units dispensed $(\mathbf{n})$ & Specific medications/items \\
\hline Steroids (topical) & 31 & $1 \%$ Hydrocortisone $(n=15), 0.1 \%$ triamcinolone $(n=15)$, taclonex $(n=1)$ \\
Antifungals (topical) & 30 & Clotrimazole $(n=19)$, tolnaftate $(n=10)$, nystatin $(n=1)$ \\
Emollients & 16 & Lotion $(n=10)$, absorbase $(n=3)$, calamine lotion $(n=2)$, zinc cream $(n=1)$ \\
Personal care items & 12 & Socks $(n=8)$, bandaids $(n=3)$, sunscreen $(n=1)$ \\
Anti parasitics (topical) & 9 & Permethrin cream \\
Antibiotics (topical) & 8 & Triple antibiotic cream \\
Antihistamines (oral) & 8 & Diphenhydramine \\
Antibiotics (oral) & 6 & Doxycycline $(n=4)$, cephalexin $(n=2)$ \\
Analgesia & 5 & lbuprofen $(n=2)$, acetaminophen $(n=3)$ \\
\hline
\end{tabular}

First, over half of patients with an ethnicity recorded were not identified as Caucasian, compared with $27 \%$ of the homeless patients in the southern California study [11]. Skin cancer is less prevalent in darkerskinned populations, although it is a frequently missed diagnosis [12]. Additionally, most patient encounters in our study included complaints of acute pain or pruritus $(n=118,86.7 \%)$, which indicates that patients most often seek medical treatment at the clinic for relief of discomfort. Actinic keratosis and early-stage skin cancers are frequently asymptomatic and therefore patients may not request evaluation. The southern California study included only patients who were referred to the dermatology clinic, and thus these referrals may have led to a bias in the number of skin cancers detected [11].

Dermatologic complaints of the lower extremity were common in this study. These findings are consistent with other published studies: for example, unhoused injured patients presenting to the ED most commonly have lower extremity injuries, whereas housed injured patients presenting to the ED most commonly have upper extremity injuries [13]. In particular, tinea pedis and chronic wounds were common diagnoses. Homeless individuals often have ill-fitting shoes, difficulty performing foot and nail hygiene, and spend disproportionate time sitting, standing or walking, with resulting venous stasis. This combined with common comorbidities in the homeless such as neuropathy secondary to alcohol or diabetes and ischemia from arteriosclerosis may predispose to infections and poor wound healing $[14,15]$.
There are several limitations to this study. First, homeless populations in different parts of the country face differing climate conditions, local infections, and may have differing ethnic and sociodemographic elements, limiting generalizability. A second limitation is that all diagnoses were made visually at the clinic. Due to limited resources, biopsies, $\mathrm{KOH}$ microscopy for tinea, bacterial and fungal culture, and other simple diagnostic tools were not available. This could have resulted in some misclassification of the dermatologic conditions seen, particularly during clinics without a dermatologist present. Third, and perhaps the largest limitation of our study, is that it was done retrospectively, and exams were complaintfocused, rather than full-body skin exams. Full skin exams are rarely conducted at the clinic, due in part to the relative lack of privacy at the homeless shelter. Therefore, additional diagnoses may have been missed, particularly actinic keratosis and skin cancers, which may not be associated with pain, itch, or functional impairment. Finally, the prevalence of skin diagnoses in our population may be artificially high, as the twice-a-month dermatology clinic providers actively seek out patients with skin complaints from among the homeless shelter clients.

By understanding skin diseases common in this population, shelter-based clinics can better serve unhoused individuals by focusing resources on services that more closely meet their needs. In fact, simple and inexpensive interventions for dermatologic problems based on prevalence data from homeless populations 


\section{www.odermatol.com}

may be used to broadly improve the quality and availability of dermatologic services designed to reach these patients. Providers caring for the homeless may use this study as a guide in selecting dermatologic medications and supplies to offer at shelters and homeless clinics. In addition, given the high prevalence of skin disorders affecting the lower extremity, foot care should be a focus of health programs for these individuals, and shoes should be removed and lower extremities examined at every medical visit.

\section{REFERENCES}

1. Henry M, Cortes A, Morris S. The 2013 annual homelessness assessment report (AHAR) to congress: part 1, point-in-time estimates of homelessness. 2013.

2. Gelberg L, Linn LS, Usatine RP, Smith MH. Health, homelessness, and poverty; a study of clinic users. Arch Intern Med. 1990;150:2325-30.

3. Moy JA, Sanchez MR. The cutaneous manifestations of violence and poverty. Arch Dermatol. 1992;128:829-39.

4. O’Toole TP, Johnson EE, Redihan S, Borgia M, Rose J. Needing primary care but not getting it: the role of trust, stigma and organizational obstacles reported by homeless veterans. J Health Care Poor Underserved. 2015;26:1019-31.

5. Crane M, Warnes AM. Primary health care services for single homeless people: defects and opportunities. Family Practice. 2001;18:272-76.

6. Kouris A, Christodoulou C, Efstathiou V, Tsatovidou R, TorlidiKordera E, Zouridaki E, et al. Comparative study of quality of life and psychosocial characterstics in patients with psoriasis and leg ulcers. Wound Repair Regen. 2016;24:443-46.

7. Hollestein LM, Nijsten T. An insight into the global burden of skin diseases. J Invest Dermatol. 2014;134:1499-01.

8. Fazel S, Geddes JR, Kushel M. The health of homeless people in high-income countries: descriptive epidemiology, health consequences, and clinical and policy recommendations. Lancet. 2014;384:1529-40.

9. Stratigos AJ, Stern R, Gonzalez E, Johnson RA, O'Connell J, Dover JS. Prevalence of skin disease in a cohort of shelter-based homeless men. J Am Acad Dermatol. 1999;41:197-02.

10. Badiaga S, Menard A, Tissot DH, Ravaux I, Chouquet D, Graveriau C, et al. Prevalence of skin infections in sheltered homeless. Eur J Dermatol. 2005;15:382-86.

11. Grossberg AL, Carranza D, Lamp K, Chiu MW, Lee C, Craft N. Dermatologic care in the homeless and underserved populations: observations from the venice family clinic. Cutis. 2012;89:25-32.

12. Gohara M. Skin cancer: an African perspective. Br J Dermatol. 2015;173(Suppl. 2):17-21.

13. Mackelprang JL, Graves JM, Rivara FP. Homeless in America: injuries treated in US emergency departments, 2007-2011. Int J Inj Contr Saf Promot. 2014;21:289-97.

14. Raoult D, Foucault C, Brouqui P. Infections in the homeless. Lancet Infect Dis. 2001;1:77-84.

15. Bernstein RS, Meurer LN, Plumb EJ, Jackson JL. Diabetes and hypertension prevalence in homeless adults in the United States: a systematic review and meta-analysis. Am J Public Health. 2015;105:46-60.

Copyright by Caitlin Contag, et al. This is an open-access article distributed under the terms of the Creative Commons Attribution License, which permits unrestricted use, distribution, and reproduction in any medium,provided the original author and source are credited

Source of Support: Nil, Conflict of Interest: None declared. 